\title{
Helicopter emergency medical services accident rates in different international air rescue systems
}

\author{
This article was published in the following Dove Press journal: \\ Open Access Emergency Medicine \\ 21 April 2010 \\ Number of times this article has been viewed
}

\author{
J Hinkelbein ${ }^{1,2}$ \\ M Schwalbe ${ }^{2}$ \\ H V Genzwuerker ${ }^{2,3}$ \\ 'Department for Anesthesiology \\ and Intensive Care Medicine, \\ University Hospital Cologne, \\ Germany; ${ }^{2}$ Working Group \\ "Emergency Medicine and Air Rescue", \\ German Society of Aviation and Space \\ Medicine (DGRLM) eV; ${ }^{3}$ Clinic of \\ Anesthesiology and Intensive Care \\ Medicine, Neckar-Odenwald-Kliniken \\ $\mathrm{gGmbH}$, Hospitals Buchen and \\ Mosbach, Buchen, Germany
}

Aim: Each year approximately two to four helicopter emergency medical services (HEMS) crashes occur in Germany. The aim of the present study was to compare crash rates and fatal crash rates in Germany to rates in other countries.

Materials and methods: A MEDLINE search from 1970 to 2009 was performed using combinations of the keywords "HEMS", "rescue helicopter", "accident", "accident rate", "crash", and "crash rate". The search was supplemented by additional published data. Data were compared on the basis of 10,000 missions and 100,000 helicopter flying hours. These data were allocated to specific time frames for analyis.

Results: Eleven relevant studies were identified. Five studies (three from Germany, one from the US, one from Australia) analyzing HEMS accidents on the basis of 10,000 missions were identified. Crash rates per 10,000 missions ranged between 0.4 and 3.05 and fatal crash rates between 0.04 and 2.12. In addition, nine studies (six from the US, two from Germany, one from Australia) used 100,000 flying hours as a denominator. Here, crash rates ranged between 1.7 and 13.4 and fatal crash rates between 0.91 and 4.7 .

Conclusions: Data and accident rates were inhomogeneous and differed significantly. Data analysis was impeded by publication of mean data, use of different time frames, and differences in HEMS systems.

Keywords: fatal accident rate, rescue helicopter, fatal crash rate, helicopter emergency medical system, accident analysis

\section{Introduction}

In September 1970 the first German public rescue helicopter "Christoph 1" was established at the Hospital of Munich-Harlaching. Since then, helicopter emergency medical services (HEMS) have become increasingly important in the German emergency medical system (EMS). Within one year of starting rescue missions, "Christoph 1" crashed during an approach to an emergency scene in August 1971. Two occupants were killed, one was severely injured, and the helicopter was totally destroyed. This was the first aviation accident related to civilian HEMS in Germany.

Whereas the calculated accident rate and fatal accident rate for rescue helicopter crashes was extremely high in the first years of HEMS, both have steadily decreased over the past decades. During recent years, aviation safety has additionally been improved by regulations (eg, Joint Aviation Regulations for Flight Crew Licensing and Joint Aviation Regulations for Flight Operations) and enhanced aircraft techniques (eg, newer helicopter types, better aviation instruments, and the global positioning system). Still, almost every year, two to four HEMS-related accidents/crashes occur
Correspondence: Jochen Hinkelbein Department for Anesthesiology and Intensive Care Medicine, University Hospital Cologne, Kerpener Str 62, 50937 Cologne, Germany

Tel +49 I7I 823 I385

Email jochen.hinkelbein@uk-koeln.de 
for the 82 rescue helicopters based in Germany. Some of these accidents are associated with fatal outcomes for crew members, patients, or bystanders.

This raises contrary opinions, serious concerns, and fierce disputes about the benefits for patients, ${ }^{1-4}$ effectiveness, ${ }^{5-8}$ costs, ${ }^{3,5-7}$ and especially the safety ${ }^{9,10-17}$ of the HEMS in general and compared with the ground EMS. To date, several studies have analyzed HEMS performance and HEMS accidents in other countries, but results are difficult to compare, given that different analyzing methods and different time frames are used. The aim of the present study was to compare accident rates and fatal accident rates in Germany with published rates for other countries using a time-based approach.

\section{Materials and methods}

A MEDLINE search was performed to retrieve published data on accident rates and fatal accident rates in different international HEMS systems. To identify relevant studies, all combinations of the keywords "HEMS", "rescue helicopter", "accident", "accident rate", "crash", or "crash rate" were used (Table 1). Analysis was limited from January 1st 1970 to December 31st 2009 to facilitate comparisons and to analyze only newer and not historical data before introduction of HEMS in Germany. Original contributions and reviews as well as letters to the editor, case reports, case series, and meta-analyses were analyzed. Identified studies were supplemented with published but not indexed studies. ${ }^{10,18-20}$ Studies dealing with international rescue helicopter systems and accident analysis were eligible for further data analysis. Studies not presenting accident rates were excluded from further analysis.

Table I Seven eligible studies retrieved from MEDLINE on OI January 2010*

\begin{tabular}{llll}
\hline Keywords & & $\begin{array}{l}\text { Total number of } \\
\text { eligible studies }\end{array}$ & $\begin{array}{l}\text { Eligible studies } \\
\text { for analysis }\end{array}$ \\
\hline HEMS & - & 424 & \\
& Accident & 39 & \\
& Accident rate & 14 & \\
& Crash & 2 & $7(+4)$ \\
Rescue & Crash rate & 1 & \\
helicopter & - & 404 & \\
& Accident & 126 & \\
& Accident rate & 23 & \\
& Crash & 18 & I I \\
\hline
\end{tabular}

Note: *Supplemented by four published but not indexed studies.
Data were compared on the basis of 10,000 missions completed and 100,000 helicopter flying hours. Two specialists in anesthesiology with expertise in air rescue categorized the retrieved studies independently as "eligible" or "not eligible". Consensus was achieved in three cases of discrepancy. For further analysis, data from eligible studies were allocated to the specific timeframes used and presented as time-based figures.

\section{Results}

Overall, 1053 studies were identified. Seven indexed studies were identified dealing with HEMS accidents on the basis of 10,000 missions or 100,000 flying hours. These were supplemented with four more published but nonindexed studies. ${ }^{10,18-20}$ Therefore, a total of eleven studies were analyzed. Five studies (three from Germany, ${ }^{16,18,21}$ one from the US, ${ }^{15}$ and one from Australia) ${ }^{13}$ analyzing HEMS accidents on the basis of 10,000 missions were identified (Figure 1). Crash rates per 10,000 missions ranged between 0.4 (Germany) $)^{16}$ and 3.05 (US) ${ }^{15}$ and fatal crash rates between 0.04 (Germany) ${ }^{16}$ and 2.12 (US, ${ }^{15}$ see Figure 2 and Table 2).

In addition, nine studies ( from Germany, 2,21,24 and one from Australia) ${ }^{13}$ used 100,000 flying hours as a denominator (Figure 3). Crash rates per 100,000 flying hours ranged from 1.7 (US) ${ }^{20}$ to 13.4 (US) ${ }^{19}$ and fatal crash rates between 0.91 (Germany) ${ }^{21}$ and 4.7 (US; ${ }^{24}$ see Table 3 and Figure 4).

For both accident rates and fatal accident rates on the basis of 10,000 missions, the published data range was limited to the years 1973-2004. Published data were limited to the years 1980-2004 for accident and fatal accident rates on the basis of 100,000 flying hours.

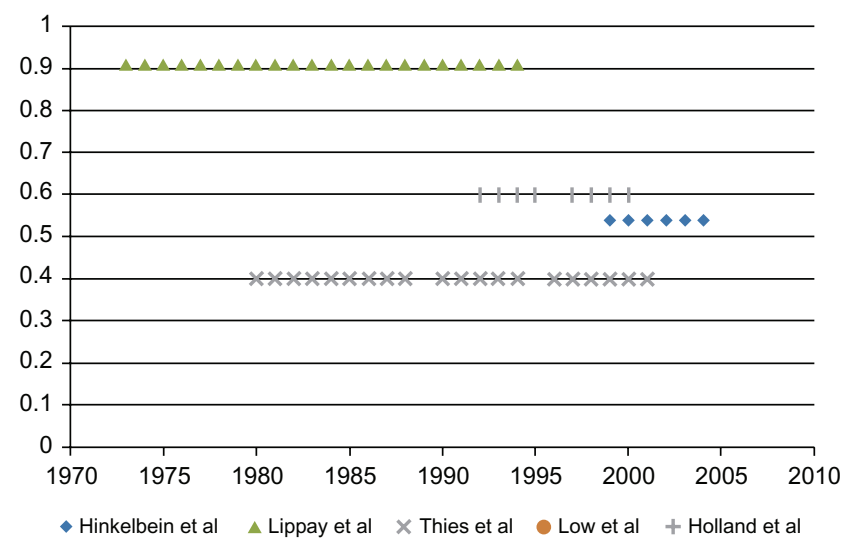

Figure I Comparison of accident rates per 10,000 missions in analyzed studies.* *Year (x-axis), accident rate per 10,000 missions (y-axis). Due to the scale of the figure, one single data point Low et al; ${ }^{15}$ accident rate per 10,000 missions $(3,05)$ is not presented. 


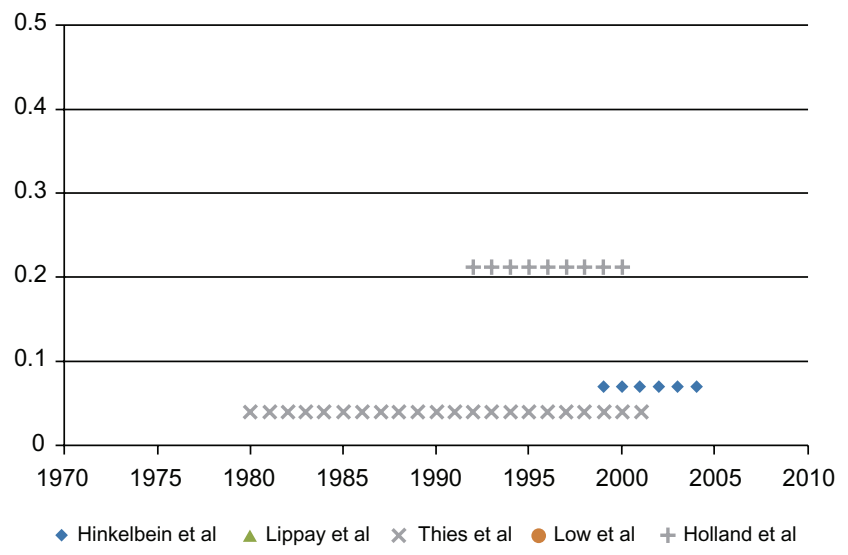

Figure 2 Comparison of fatal accident rates per 10,000 missions in analyzed studies.*

Note: *Year (x-axis), fatal accident rate per 10,000 missions (y-axis). Due to scale of figure, one data point Low et al, ${ }^{15}$ fatal accident rate per 10,000 missions $(2,12)$ is not presented.

\section{Discussion}

Compared with other aviation areas, the risk profile for HEMS is clearly increased (eg, bad weather, unknown landing site, and stress). ${ }^{15,24,25}$ This explains the higher accident rate found for HEMS compared with commercial or private aviation. ${ }^{24,25}$ Unfortunately, the published data are scarce compared with the growing HEMS services in several other European countries, eg, Austria, the UK, Norway, Poland, Switzerland, as well as other countries worldwide.

\section{Data analysis per 10,000 missions}

For HEMS missions in Germany, an accident rate of 0.40 to 0.91 versus 0.04 to 0.07 for fatal accidents was found per 10,000 missions (Table 2, Figure 1). ${ }^{21}$ These data show no relevant differences to other recently published studies $^{16,24}$ analyzing HEMS accidents between 1973 and 2004. Holland et $\mathrm{al}^{13}$ analyzed a 10 -year period with 51,164 missions for HEMS in Australia. They reported a similar accident rate per 10,000 missions $(0.60$ versus 0.20 for fatal accidents). Although both systems and regional structures

Table 2 Comparison of HEMS accidents and fatal accidents per 10,000 missions

\begin{tabular}{lllll}
\hline Study & Country & $\begin{array}{l}\text { Time } \\
\text { frame }\end{array}$ & $\begin{array}{l}\text { Accident } \\
\text { rate per } \\
10,000 \\
\text { missions }\end{array}$ & $\begin{array}{l}\text { Fatal } \\
\text { accident rate } \\
\text { per 10,000 } \\
\text { missions }\end{array}$ \\
\hline Holland $^{13}$ & Australia & $1992-2002$ & 0.60 & 0.20 \\
Lippay $^{18}$ & Germany & $1973-1994$ & 0.91 & $\mathrm{NA}$ \\
Thies $^{16}$ & Germany & $1980-2001$ & $0.40^{\dagger}$ & $0.04^{\dagger}$ \\
Hinkelbein $^{21}$ & Germany & $1999-2004$ & 0.54 & 0.07 \\
Low $^{15}$ & USA & 1991 & $3.05^{\dagger}$ & $2.12^{\dagger}$ \\
\hline
\end{tabular}

Note: ${ }^{\dagger}$ Maximum and minimum data.

Abbreviations: HEMS, helicopter emergency services; NA, not accessible data.

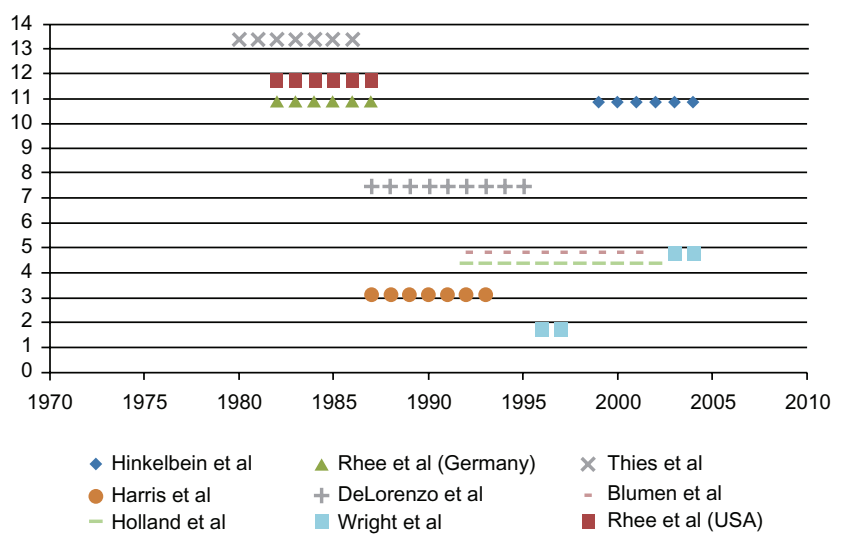

Figure 3 Comparison of accident rates per 100,000 flying hours in analyzed studies.*

Note: $*$ Year (x-axis), accident rate per 100,000 flying hours (y-axis).

are very different (short-distance rural versus long-distance desert areas), accident rates and fatal accident rates are comparable. In contrast, Low et $\mathrm{al}^{15}$ presented relevant differences on HEMS accidents in the US (3.05 and 2.12) by analyzing one single year (Figures 1 and 2). In this study they showed a strong correlation between the accident rate and pilot proficiency. Compared with the other data identified, there was a significant difference with a five-fold higher accident rate and fatal accident rate in the US than Germany and Australia. The underlying reason may potentially be a small sample size within one single year. On the other hand, these significant differences may be due to different mission types (eg, mostly secondary flights in the US and mostly primary flights in Germany), operator-specific procedures, or different national regulations applied.

Table 3 HEMS accident rates and fatal accident rates per 100,000 flying hours

\begin{tabular}{|c|c|c|c|c|}
\hline Study & Country & $\begin{array}{l}\text { Time } \\
\text { frame }\end{array}$ & $\begin{array}{l}\text { Accident } \\
\text { rate per } \\
100,000 \\
\text { flying hours }\end{array}$ & $\begin{array}{l}\text { Fatal } \\
\text { accident rate } \\
\text { per } 100,000 \\
\text { flying hours }\end{array}$ \\
\hline Holland ${ }^{13}$ & Australia & 1992-2002 & 4.38 & 1.46 \\
\hline Hinkelbein ${ }^{21}$ & Germany & 1999-2004 & 10.9 & $0.91^{\dagger}$ \\
\hline \multirow[t]{2}{*}{ Rhee $^{24}$} & Germany & 1982-1987 & 10.9 & 4.1 \\
\hline & US & |982-1987 & 11.7 & $4.7^{\dagger}$ \\
\hline NTSB $^{19}$ & US & $1980-1986$ & $13.4^{\dagger}$ & NA \\
\hline Harris $^{22}$ & US & |987-1993 & 3.1 & $1.6 \mid$ \\
\hline DeLorenzo ${ }^{23}$ & US & 1987-1995 & 7.44 & NA \\
\hline Blumen & US & |992-200| & 4.83 & 1.69 \\
\hline \multirow[t]{3}{*}{ Wright $^{20}$} & US & 1996-1997 & 1.7 & NA \\
\hline & US & $2000-2004$ & NA & 1.8 \\
\hline & US & $2003-2004$ & 4.8 & NA \\
\hline
\end{tabular}

Note: ${ }^{\dagger}$ Maximum and minimum.

Abbreviations: HEMS, helicopter emergency medical services; NA, not accessible data. 


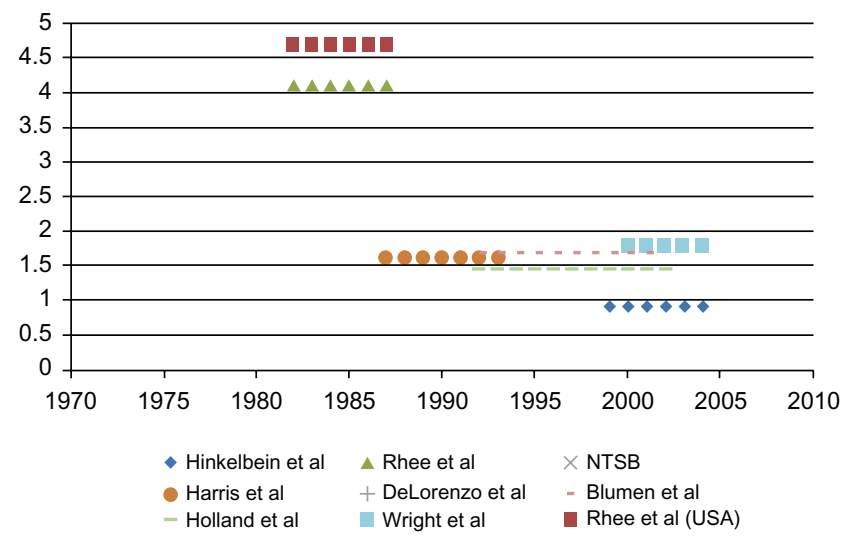

Figure 4 Comparison of fatal accident rates per 100,000 flying hours in analyzed studies.*

Note: *Year (x-axis), fatal accident rate per 100,000 flying hours (y-axis).

For an international comparison, data for accident rates on the basis of 10,000 missions were comparable for Australia ${ }^{13}$ and Germany. ${ }^{18,16,21}$ In contrast, data for the US ${ }^{15}$ varied (a fivefold higher rate), for the reasons stated above. Fatal accident rates on the basis of 10,000 missions showed the same congruencies for Australia and Germany and differences for the US.

\section{Data analysis per 100,000 flying hours}

On the basis of 100,000 flying hours, accident rates of 10.88 for all accidents and 0.91 for fatal accidents were found in a study by Hinkelbein et al for Germany (Table 3). ${ }^{21}$ In addition, another study by Rhee et al is available, in which HEMS accidents between 1982 and 1987 were presented. ${ }^{22}$ Both studies show comparable accident rates for nonfatal accidents but a nearly five-times higher fatal accident rate in the earlier study. ${ }^{21,24}$ Rhee et al found a surprisingly high fatal accident rate in their analysis (a fatality rate of 4.7 per 100,000 hours) from 1982 to 1987.

Even military HEMS data for accident rates was comparable with civilian data. DeLorenzo et $\mathrm{al}^{23}$ state a rate of 7.44 accidents per 100,000 flying hours, which is nearly the mean of all other studies identified (Table 3). For an international comparison, data for accident rates on the basis of 100,000 flying hours ranged between 1.7 and $13.4^{19,20}$ which includes rate for Australia ${ }^{13}$ and Germany. ${ }^{21,24}$ These data are inhomogeneous and vary significantly.

\section{Limitations}

Analysis of aviation accident data is often complicated by a lack of usable denominator data. ${ }^{26}$ This also applies to the analysis of HEMS accidents. On the other hand, both aircraft accidents as well as HEMS accidents underpin a highly complex error chain which depends on multiple factors.
Although a time-frame or time-based approach was used to exclude multiple influences, different pilot qualifications, ${ }^{24}$ environmental factors, as well as human factors cannot be evaluated adequately in a retrospective study. Both primary (emergency) and secondary (interhospital transfer) missions were analyzed, although there may be some different operating conditions with potentially different accident rates.

Data on the basis of 10,000 missions or 100,000 flying hours should be in concordance for each country analyzed. This point does not apply in the present study. One possible reason may be differences in the duration of a mission (long versus short) in different countries. Unfortunately these data are not published. Using statistical approaches to analyze different rates in various countries would be beneficial for data interpretation. Unfortunately, some of the studies reported only rates but not absolute numbers (eg, number of missions or flying hours). Therefore, specific statistical tests were not possible.

\section{Conclusions}

Published data for three countries were identified. Data analysis was impeded by publication of mean data, use of different time frames, and differences in HEMS systems. Nevertheless, the data in the present study are essential to evaluate the accident risk with an HEMS mission. In the future, publication of accident data and studies analyzing the complete time-frame of HEMS missions are required. Additionally, it may be beneficial to record HEMS accident data in detail in a specific database. Besides relevant denominator data (eg, number of missions or flying hours), potential confounding factors (eg, weather conditions, urban versus rural missions, and aircraft maintenance) are of special interest. This approach would facilitate detailed and valid analyses of HEMS accidents. If these data remain inaccessible, future studies may encounter similar interpretation difficulties.

\section{Disclosures}

The authors report no conflicts of interest in this work.

\section{References}

1. Baxt WG, Moody P. The impact of a rotorcraft aeromedical emergency care service on trauma mortality. JAMA. 1983;249:3047-3051.

2. Biewener A, Aschenbrenner U, Rammelt S, Grass R, Zwipp H. Impact of helicopter transport and hospital level on mortality of polytrauma patients. J Trauma. 2004;56:94-98.

3. Braithwaite CE, Rosko M, McDowell R, Gallagher J, Proenca J, Spott MA. A critical analysis of on-scene helicopter transport on survival in a statewide trauma system. J Trauma. 1998;45:140-144.

4. Hawkins SC, Morgan S, Waller A, Winslow T, McCoy M. Effects of ground EMS and ED personnel on air medical trauma on-site times. Air Med J. 2001;20:32-36. 
5. Cunningham P, Rutledge R, Baker CC, Clancy TV. A comparison of the Association of Helicopter and Ground Ambulance Transport with the outcome of injury in trauma patients transported from the scene. J Trauma. 1997;43:940-946.

6. Dodd RS. The cost-effectiveness of air medical helicopter crash survival enhancements. An evaluation of the costs, benefits and effectiveness of injury prevention interventions. Air Med J. 1994;13:281-293.

7. Gearhart PA, Wuerz R, Localio AR. Cost-effectiveness analysis of helicopter EMS for trauma patients. Ann Emerg Med. 1997;30: 500-506.

8. Shatney CH, Homan SJ, Sherck JP, Ho CC. The utility of helicopter transport of trauma patients from the injury scene in an urban trauma system. J Trauma. 2002;53:817-822.

9. Baker SP, Grabowski JG, Shanahan DF, Lamb MW, Li GH. EMS helicopter crashes: What influences fatal outcome? Ann Emerg Med. 2006;47:351-356

10. UCAN Safety Committee. Air Medical Physician Handbook. November 2002 Supplement. Salt Lake City, UT: Air Medical Physician Association; 2002.

11. Dodd RS. EMS helicopter safety revisited. Hosp Aviat. 1989;8:6-8.

12. Garner AA, Keetelaar DM, Konemann J. Safety of emergency medical service helicopters. Med J Aust. 2005;182:12 (Editorial).

13. Holland J, Cooksley DG. Safety of helicopter aeromedical transport in Australia: A retrospective study. Med J Aust. 2005;182:17-19.

14. Isakov AP. Souls on Board: Helicopter emergency medical services and safety. Ann Emerg Med. 2006;47:357-360.

15. Low RB, Dunne MJ, Blumen IJ, Tagney G. Factors associated with the safety of EMS helicopters. Am J Emerg Med. 1991;9:103-106.

16. Thies KC, Sep D, Derksen R. How safe are HEMS-programmes in Germany? A retrospective analysis. Resuscitation. 2006;68:359-363.
17. Wuerz RC, O'Neal R. Role of pilot instrument proficiency in the safety of helicopter emergency medical services. Acad Emerg Med. 1997;4:972-975.

18. Lippay C. Hubschrauberunfälle im Rettungseinsatz. Rettungsdienst. 1996;19:14-18. German.

19. National Transportation Safety Board. Commercial emergency medical services helicopter operations. Report No. SS-88/01. Washington, DC: NTSB; 1988.

20. Wright RM Jr. Air medical service, an industry under scrutiny. Rotor. Winter 2004-2005:6-8.

21. Hinkelbein J, Dambier M, Viergutz T, Genzwuerker HV. A six-year analysis of German emergency medical services helicopter crashes. J Trauma. 2008;64:204-210.

22. Harris JS. US hospital-based EMS helicopter accident rate declines over the most recent seven-year period. Helicopter Safety. 1994;20:1-7.

23. Lorenzo RA De, Freid RL, Villarin AR. Army aeromedical crash rates. Mil Med. 1999;164:116-118.

24. Rhee KJ, Holmes EM 3rd, Moecke HP, Thomas FO. A comparison of emergency medical helicopter accident rates in the United States and the Federal Republic of Germany. Aviat Space Environ Med. 1990;61:750-752.

25. Adams RJ, MacConkey ED. Aeronautical decision making for air ambulance administrators. Natl Tech Inform Serv. 1990. Available from: http://oai.dtic.mil/oai/oai?verb=getRecord\&metadataPrefix= html\&identifier=ADA219404. Accessed on March 31, 2010.

26. Hinkelbein J, Dambier M, Schwalbe M, Glaser E, Neuhaus C. Lack of denominator data in aviation accident analysis. Aviat Space Environ Med. 2010;81:77.
Open Access Emergency Medicine

\section{Publish your work in this journal}

Open Access Emergency Medicine is an international, peer-reviewed, open access journal publishing original research, reports, editorials, reviews and commentaries on all aspects of emergency medicine. The manuscript management system is completely online and includes a very quick and fair peer-review system, which is all easy to use.

\section{Dovepress}

Visit http://www.dovepress.com/testimonials.php to read real quotes from published authors. 